\title{
Charging Design and Experimental Research on Gas Generant of an Handheld Fire Extinguishing Bomb
}

\author{
Xinying Cheng ${ }^{1, a^{*}}$, Hongwei Zhuang ${ }^{1, b}$, Kaiwei Zuo ${ }^{1, c}$ and Xin Liu ${ }^{1, d}$ \\ ${ }^{1}$ China's shaanxi province xi'an armed police engineering university \\ a574909016@qq.com, bcaojingyi01@163.com, '352928752@qq.com, d243886357@qq.com
} Keywords: Gas generant; Design; Gas generant properties; The highest temperature;
Experimental research

\begin{abstract}
Based on the structure characteristics of miniaturization, portable, a non pressure-accumulated and handheld fire extinguishing bomb was designed, using hot aerosol to inject ultrafine powder. In order to achieve better gas driving force, at the same time inhibit the high temperature caused by hot aerosol, and firstly gas generant was designed for charging. Secondly the experimental research on the gas generant performance was done for optimizing. Finally by the temperature test platform that was independently designed, the experimental research on the temperature change of the extinguishing agent at the outlet and handle was done. Experiments show that the performance of optimized gas generant is better, because the specific volume is bigger, $340 \mathrm{ml} / \mathrm{g}$, the combustion heat value is lower, $2920 \mathrm{~J} / \mathrm{g}$, and vacuum stability is better, $0.42 \mathrm{ml} / \mathrm{g}$; And safety of fire extinguishing bomb is better, because the highest temperature at the outlet is less than $60^{\circ} \mathrm{C}$, and the highest temperature at the handle is less than $40^{\circ} \mathrm{C}$.
\end{abstract}

\section{Introduction}

With the continuous development of aerosol fire extinguishing technology, fire-fighting effectiveness has also been rapidly improved, especially in portable hot aerosol fire extinguishers, making its advantage obviously. However, the hot aerosol fire extinguishing agent belongs to energetic materials, it is an exothermic reaction during the combustion. Although it was handled by physical and chemical methods of cooling, the temperature of nozzle is still high about $200{ }^{\circ} \mathrm{C}$.It is easily to bring secondary fire damage to target. At the same time, the rise of shell temperature will bring scald damage to the operator.

In this paper, the handheld portable fire bombs designed for the cold and hot aerosol technology. In order to achieve better gas thrust, while suppressing the high temperature that aerosol brought, and taken a variety of cooling approaches and charge designs: (1) Reduce gas dosage to reduce the total heat and temperature; (2) Improved gas agent component, in order to reduce the heat of combustion and increase the gas production rate about unit mass of gas generating product;(3) Use the cooling function of cold aerosol to reduce the temperature of nozzle of fire extinguishing agent. Finally, make a study about optimizing the gas generating product performance. And experimental study about changes in nozzle temperature and handle temperature.

\section{Charge Design of Fire Extinguishing Bomb's Gas Generating Product}

Gassing Agent Type Selection. Generally, the gas generating agent is lited by igniter. It quickly burn and produce high temperature and pressure(HTHP) gas. Promote fine dry powder injectionand put out a fire, is the power source throughout the elastomer. The type of gas extinguishing bombs used in thermal aerosol fire extinguishing agent. The product contains about $70 \%$ of the gas phase component as aerodynamic. There are $\mathrm{N}_{2}, \mathrm{CO}_{2}, \mathrm{H}_{2} \mathrm{O}$, etc., in addition to containing about $30 \%$ of the solid particles. The average particle diameter of $1 \mu \mathrm{m}$ or less, with the nature of the gas, can bypass obstacles, and suspended in a space long and difficult to settle. The main product of $\mathrm{C}$ and $\mathrm{K}_{2} \mathrm{O}$, $\mathrm{K}_{2} \mathrm{CO}_{3}, \mathrm{KHCO}_{3}$, can be reached certain aid firefighting purposes endothermic by decomposition cooling, gas chemical suppression, solid phase chemical suppression and so on. In order to achieve 
hot and cold aerosol fire extinguishing aerosol complex interaction effect.

For hot aerosol fire extinguishing agent, in accordance with the use of primary oxidant components can be divided into $\mathrm{K}$-type (in $\mathrm{KNO}_{3}$-based) and $\mathrm{S}$-type (with $\mathrm{Si}\left(\mathrm{NO}_{3}\right)$ 2-based). Extinguishing mechanism both from the principle is the same, but its fire effectiveness is not the same. Extinguishing Effectiveness size comparison of $\mathrm{K}$ salt and $\mathrm{S}$ salts:

$\mathrm{K}$ Salt $>$ A mixture of $\mathrm{K}$ salt and $\mathrm{S}$ salt $>\mathrm{S}$ salt

Therefore, choose $\mathrm{K}$ type as a hot aerosol fire extinguishing agent type.

Basic Formula of Negative Oxygen Balance Design. For K-type aerosol fire extinguishing agent, do negative oxygen balance design based on fire extinguishing agent of portable aerosol fire extinguisher that has already been developed comparatively mature in domestic. That is, the oxidizing agent is $\mathrm{KNO}_{3}$, flammable agent is $\mathrm{C}_{3} \mathrm{H}_{6} \mathrm{~N}_{6}$, phenolic resin as binder both, but also for flammable agents. According pyrotechnic polymer using a monomer in the calculation, where a phenolic resin which uses monomer $\mathrm{C}_{13} \mathrm{H}_{12} \mathrm{O}_{2}$.

According to a ternary mixture:

$A+B+C=100$

$A-$ The quality of oxidant in the medicament, unit: $g$;

$B$ - The quality of combustible agent in the medicament, unit: $g$;

$C$ - The quality of additive in the medicament, unit: $g$;

$a$ - The quality of $1 \mathrm{~g}$ oxygen decomposition of oxidant required, unit: $g$;

$b$ - The quality of $1 \mathrm{~g}$ oxygen decomposition of combustible agent required, unit: $g$;

$c$ - The quality of $1 \mathrm{~g}$ oxygen decomposition of additive required, unit: $g$;

Each ingredient will decompose or burn complete reaction equation in the following table:

Table 1 The ingredients complete reaction equation

\begin{tabular}{|c|l|c|c|}
\hline \multicolumn{2}{|c|}{ composition } & $\begin{array}{c}\text { Decomposition / combustion } \\
\text { equation }\end{array}$ & mass/g \\
\hline Oxidant & $\mathrm{KNO}_{3}$ & $2 \mathrm{KNO}_{3}=\mathrm{K}_{2} \mathrm{O}+\mathrm{N}_{2}+2.5 \mathrm{O}_{2}$ & $\mathrm{a}=2.53$ \\
\hline $\begin{array}{c}\text { Combusti } \\
\text { ble agent }\end{array}$ & $\mathrm{C}_{3} \mathrm{H}_{6 \mathrm{~N}}$ & $\mathrm{C}_{3} \mathrm{H}_{6} \mathrm{~N}_{6}+4.5 \mathrm{O}_{2}=3 \mathrm{CO}_{2}+3 \mathrm{H}_{2} \mathrm{O}+3 \mathrm{~N}_{2}$ & $\mathrm{~b}=0.73$ \\
\hline Binder & $\mathrm{C}_{13} \mathrm{H}_{12} \mathrm{O}_{2}$ & $\mathrm{C}_{13} \mathrm{H}_{12} \mathrm{O}_{2}+15 \mathrm{O}_{2}=13 \mathrm{CO}_{2}+6 \mathrm{H}_{2} \mathrm{O}$ & $\mathrm{c}=0.42$ \\
\hline
\end{tabular}

Negative oxygen balance agents commonly used oxygen difference (n) to indicate the quantity of oxygen. That is, the difference between oxygen demand and pharmacy oxygen in $100 \mathrm{~g}$ pyrotechnic,complete oxidation of all flammable agents.

For the above composition formula, the mass fraction of phenol resin taken $10 \%$. In order to have a convenient calculation, set $\mathrm{C}$ about $10 \mathrm{~g}$, when $\mathrm{n}$ were $0,-10,-20,-30,-40$. Conduct negative oxygen (including zero oxygen) balanced design:

$$
\begin{aligned}
& A=\left(n+\frac{90}{b}+\frac{10}{c}\right) \times \frac{a \times b}{a+b} \\
& B=90 \mathrm{I} A
\end{aligned}
$$

And to establish the approximate chemical equation based on conservation of mass and balance constant method:

(1) when $\mathrm{n}=0, \mathrm{~A}=83.34 \mathrm{~g}, \mathrm{~B}=6.66 \mathrm{~g}$

$2 \mathrm{KNO}_{3}+0.128 \mathrm{C}_{3} \mathrm{H}_{6} \mathrm{~N}_{6}+0.121 \mathrm{C}_{13} \mathrm{H}_{12} \mathrm{O}_{2} \rightarrow \mathrm{K}_{2} \mathrm{O}+1.384 \mathrm{~N}_{2}+1.11 \mathrm{H}_{2} \mathrm{O}+1.957 \mathrm{CO}_{2}$

(2)when $\mathrm{n}=-10, \quad \mathrm{~A}=77.67 \mathrm{~g}, \mathrm{~B}=12.33 \mathrm{~g}$

$2 \mathrm{KNO}_{3}+0.25 \mathrm{C}_{3} \mathrm{H}_{6} \mathrm{~N}_{6}+0.13 \mathrm{C}_{13} \mathrm{H}_{12} \mathrm{O}_{2} \rightarrow \mathrm{K}_{2} \mathrm{O}+1.75 \mathrm{~N}_{2}+1.53 \mathrm{H}_{2} \mathrm{O}+1.15 \mathrm{CO}+1.29 \mathrm{CO}_{2}$

(3)when $\mathrm{n}=-20, \quad \mathrm{~A}=72.00 \mathrm{~g}, \mathrm{~B}=18.00 \mathrm{~g}$ 
$2 \mathrm{KNO}_{3}+0.4 \mathrm{C}_{3} \mathrm{H}_{6} \mathrm{~N}_{6}+0.14 \mathrm{C}_{13} \mathrm{H}_{12} \mathrm{O}_{2} \rightarrow \mathrm{K}_{2} \mathrm{O}+2.2 \mathrm{~N}_{2}+2.04 \mathrm{H}_{2} \mathrm{O}+2.80 \mathrm{CO}+0.22 \mathrm{CO}_{2}$

(4)when $\mathrm{n}=-30, \quad \mathrm{~A}=66.34 \mathrm{~g}, \mathrm{~B}=23.66 \mathrm{~g}$

$2 \mathrm{KNO}_{3}+0.57 \mathrm{C}_{3} \mathrm{H}_{6} \mathrm{~N}_{6}+0.15 \mathrm{C}_{13} \mathrm{H}_{12} \mathrm{O}_{2} \rightarrow \mathrm{K}_{2} \mathrm{O}+2.71 \mathrm{~N}_{2}+2.61 \mathrm{H}_{2} \mathrm{O}+0.97 \mathrm{C}+2.69 \mathrm{CO}$

(5)when $\mathrm{n}=-40, \quad \mathrm{~A}=60.67 \mathrm{~g}, \mathrm{~B}=29.33 \mathrm{~g}$

$2 \mathrm{KNO}_{3}+0.78 \mathrm{C}_{3} \mathrm{H}_{6} \mathrm{~N}_{6}+0.17 \mathrm{C}_{13} \mathrm{H}_{12} \mathrm{O}_{2} \rightarrow \mathrm{K}_{2} \mathrm{O}+3.34 \mathrm{~N}_{2}+3.36 \mathrm{H}_{2} \mathrm{O}+2.57 \mathrm{C}+1.98 \mathrm{CO}$

Comparison of the Base Formulation Hematocrit. The size of specific volume is an important performance parameter to evaluate the size of units mass gassing agent . The volume under standard conditions about gas combustion products after $1 \mathrm{~g}$ gas generating product burn. Common V0 represents, Units of $\mathrm{ml} / \mathrm{g}$. From the ability to do work is concerned, under the same conditions, the greater the hematocrit, the stronger the ability to do work. According to the balance of the composition of the products of combustion, can seeking specific volume of gas produced agent by Avogadro's law. The equation is as follows:

$$
V_{0}=\frac{22.4 n \times 1000}{M}
$$

V0-- The size of the unit mass of the gas generating agent contained in gas production, $\mathrm{ml} / \mathrm{g}$;

$\mathrm{n}-\mathrm{T}$ The total number of moles of product gaseous components, mol;

$\mathrm{M}-\mathrm{The}$ mass of gas generating product before reaction, $\mathrm{kg}$;

22.4-- under standard conditions, the gas molar volume.

The formulation of $a, b$ values were substituted into the equation to give the following table:

Table 2 Comparison of specific volume (H2O liquid)

\begin{tabular}{|c|c|c|c|c|c|}
\hline Formula & 1 & 2 & 3 & 4 & 5 \\
\hline $\begin{array}{c}\text { Specific } \\
\text { volume L/g }\end{array}$ & 8.8 & 30 & 41 & 39 & 35 \\
\hline
\end{tabular}

By comparison it can be found, under certain preconditions about the adhesive mass fraction of $10 \%$. For the design of the formula, with the decrease of the relative content of the oxidizing agent. The hematocrit has been a change after the first increases and then decreases. Therefore we use the maximum specific volume of formulation 3 as a basis formulation. Its has large gas, high pressure, and strong push.

However, due to the negative oxygen balance, it needs oxygen in the air to participate in the reaction. Resulting in insufficient oxygen combustion, the actual burning rate is slow. Therefore, its need to optimize the design of the selected recipe. At the same time,appropriate concentration of additives can enhance gas production rate and reduce the heat of combustion.

Formulation Optimization Design. Add a low-cost base formulation to increase gas production nitroguanidine. And add a small amount of oxidizer of potassium perchlorate that can increase the burning rate, and single-base propellant that have a fewer oxygen consumption.

Under the premise of the selected basic formula $100 \mathrm{~g}$, the total amount of ingredients added control in about $10 \mathrm{~g}$. Therefore, we will factor the three components of the columns two levels, that is Single drug factor were added $2 \mathrm{~g}, 4 \mathrm{~g}$ two levels. Nitroguanidine were added $3 \mathrm{~g}, 6 \mathrm{~g}$ two levels. Potassium perchlorate were added $2.5 \mathrm{~g}$, $5 \mathrm{~g}$ two levels.

During the test, design by orthogonal experiment, preferred representative test. That is, the two levels of single base propellant, respect for A1, A2. Nitroguanidine respect for B1, B2, perchlorate respect for $\mathrm{C} 1, \mathrm{C} 2.2^{3}=9$ times can be reduced to four test trials. Following its test model $L_{4}\left(2^{3}\right)$ : 


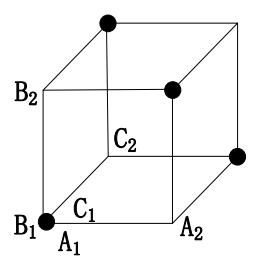

Figure 1. $\boldsymbol{L}_{4}\left(2^{3}\right)$ Model

The design formula shown in the following table.

Table 3 Optimizing the design formula

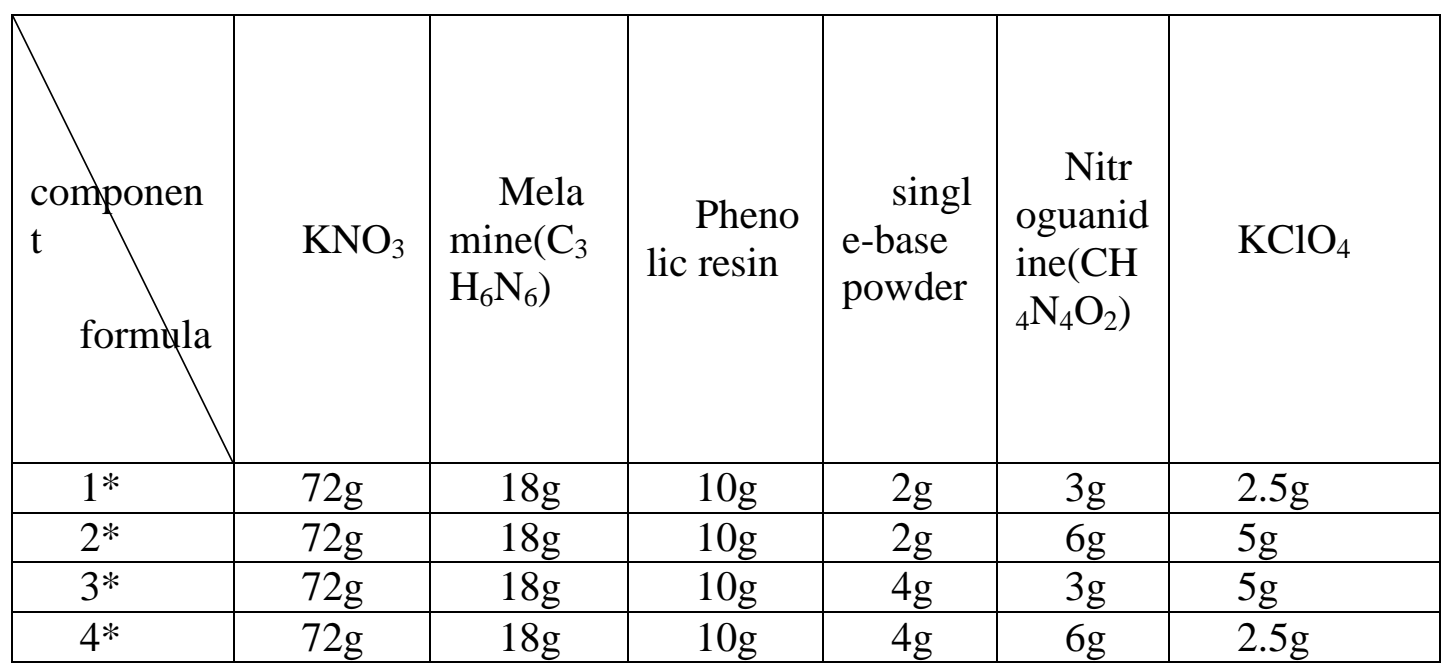

Gas-grain Structural Design. Suitable charge density can ensure the mechanical strength of grain and uniform combustion speed. Suitable combustion surface size, is the key of designed to charge the mold and pressing grains. Here, the determination pressure medicine density $1.5 \mathrm{~g} / \mathrm{ml}$, diameter $18 \mathrm{~mm}$, height $20 \mathrm{~mm}$, quality $10 \mathrm{~g}$. The top surface of the front chisel grain diameter of $5 \mathrm{~mm}$, round table groove depth $4 \mathrm{~mm}$, bottom diameter of $8 \mathrm{~mm}$. It may expand the ignition area. Conducive spot gunpowder to ignite gas Grains reliable.

Its structure is shown below:
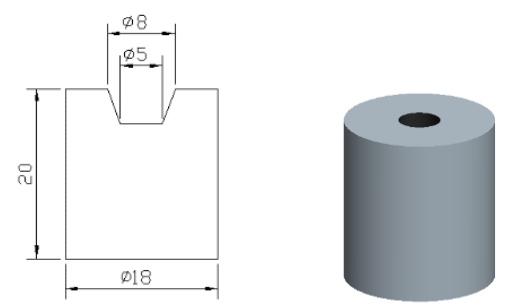

Figure 2. Gassing agent column chart

\section{Performance Test}

Gassing Agent Performance Test. Formulation of the above four groups of performance test, test their hematocrit, calorific value and vacuum stability. Comparison of experimental data shown in the following table: 
Table 4 Experimental comparison

\begin{tabular}{|c|c|c|c|}
\hline $\begin{array}{l}\text { Form } \\
\text { ula }\end{array}$ & $\begin{array}{l}\text { Specif } \\
\text { ic } \\
\text { volumem } \\
1 / g\end{array}$ & $\begin{array}{l}\quad \text { Calor } \\
\text { ific } \\
\text { value } \\
\mathrm{J} / \mathrm{g}\end{array}$ & $\begin{array}{c}\text { Vacuum } \\
\text { stability } \mathrm{ml} / \mathrm{g}\end{array}$ \\
\hline $\begin{array}{l}\text { Form } \\
\text { ula } 1 *\end{array}$ & 303 & 2885 & 0.4 \\
\hline $\begin{array}{l}\text { Form } \\
\text { ula } 2 *\end{array}$ & 322 & 2950 & 0.5 \\
\hline $\begin{array}{l}\text { Form } \\
\text { ula } 3 *\end{array}$ & 340 & 2920 & 0.6 \\
\hline $\begin{array}{l}\text { Form } \\
\text { ula } 4 *\end{array}$ & 337 & 2980 & 0.2 \\
\hline
\end{tabular}

By contrast, we found that all recipes combustion stability, Formula $3 *$ and $4 *$ hematocrit are larger, formula $3 *$ calorific value are lower.So heat generated per unit mass is not too large, and the vacuum stability is better, better thermal decomposition. Thus, the selection of the gas generating agent formulation $3 *$ design, the final content of each component in the order of: KNO3 $64.3 \%$, Melamine (C3H6N6)16.0\%, Phenolic resin 8.9\%, Single-based medicine 3.6\%, Nitroguanidine (CH4N4O2)2.7\%、 Kcl044.5\%.

Temperature Safety Performance Test. To verify the extinguishing agent to handle temperature and nozzle temperature is safe.Do safety test on the handle portion and the spout parts of the temperature.

Test Instruments

Multiple fire bombs, two UT325 digital thermometer, two K-type thermocouple.

Test procedure

Connect the instrument. The two K-type thermocouple plug are connected to the two digital thermometer jack. And the thermocouple probe are fixed to the outer wall vents and fire bombs at the handle. Start and recorded. Start jet recording extinguishing agent from the injection start to the injection is completed within a period of time. Nozzle temperature T1 and T2 handle temperature changes with time. Through digital thermometer automatic memory function, the data is recorded. Temperature safety performance test procedures see as 5:

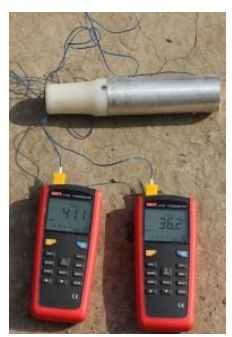

(a)Connect the instrument

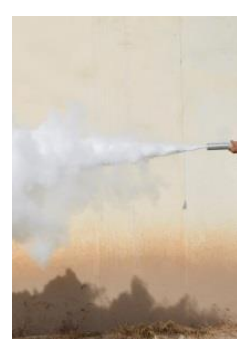

(b)Start jet

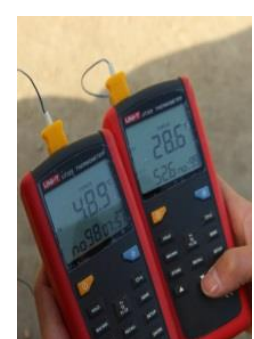

(c)Record data

Figure 3. Temperature safety performance test

(3) Test Results

Drawing nozzle temperature $\mathrm{T} 1$ and the temperature $\mathrm{T} 2$ handle curve with time $\mathrm{t}$, as shown in Fig. 4: 


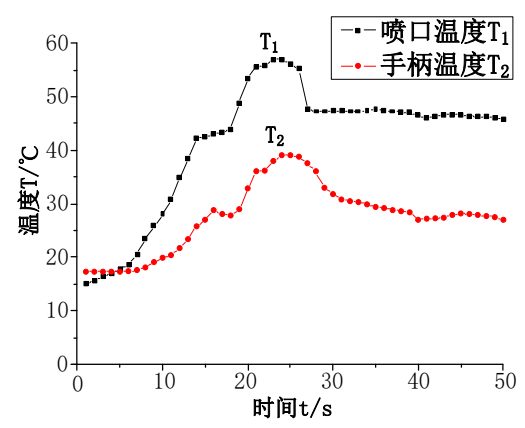

Figure 4. $\mathrm{T} \sim \mathrm{t}$ curve

Fig. 4 shows: spout highest temperature $57.1^{\circ} \mathrm{C}$, rapidly fuse with the ambient temperature, human security is better; Handle a maximum temperature of $39.1{ }^{\circ} \mathrm{C}$, the operator's hand better safety.

\section{Conclusions}

Based on gas agents charge designed to determine the final mass fraction of each component were: $\mathrm{KNO}_{3}$ 64.3\%, Melamine $\left(\mathrm{C}_{3} \mathrm{H}_{6} \mathrm{~N}_{6}\right) 16.0 \%$, Phenolic resin 8.9\%, Single-based medicine 3.6\%, Nitroguanidine $\left(\mathrm{CH}_{4} \mathrm{~N}_{4} \mathrm{O}_{2}\right) 2.7 \%, \mathrm{Kcl} 044.5 \%$.

Optimize the formulation after good gas properties, the specific volume is large. To $340 \mathrm{ml} / \mathrm{g}$, low heat of combustion values for $2920 \mathrm{~J} / \mathrm{g}$, preferably vacuum stability, is $0.6 \mathrm{ml} / \mathrm{g}$.

Fire bombs injection safety is better, spout maximum temperature of $57.1{ }^{\circ} \mathrm{C}$, the handle a maximum temperature of $39.1{ }^{\circ} \mathrm{C}$.

\section{References}

[1] Qiang Li, Jun Wangshao, Can Zhang ,The application of heat aerosol fire extinguishing apparatus ,J.Fire Science and Technology, ,32 (2013): 69-71.

[2] Hongbao Guo, Yue, Other aerosol fire extinguishing technology, Beijing: Chemical Industry Press, 2005.

[3] Guohong Bao, Zhenping Deng,So on a hand-held aerosol fire extinguishing devices: CN, 201755360 U [P] 2011-03-09..

[4] Zhiping Yan, Qiong Zhu, Et al. Research Energetic gas generating agent on the superfine extinguishing agent release effect of [J]. Blasting equipment, 37 (2008): 4-7.

[5] Zhiming Du, double Zhao, Fireworks and other aerosols, dry powder fire extinguishing agent fire extinguishing apparatus complex:. CN200510082726.5, P.2005-11-16.

[6] Guodong Liang,Cold aerosols and thermal aerosol fire extinguishing agent in extinguishing the fire in the tunnel ,J. Shanxi Science and Technology, 28 (2013): 146-147.

[7] Jiang Xiao Nan, Zhu Chenguang, Other aerosol fire extinguishing coolant filtration layer,J. Safety and Health, Fire Science and Technology, 32 (2013): 652-655.

[8] Gong Pan, Shuo Yang. Pyrotechnics science, Beijing Institute of Technology Press, 2004.

[9] Jingli Zhu, Panren Ming, Wenfang Zheng. Influence flammable aerosol fire extinguishing agent agent on the combustion temperature, J.Fire Science and Technology, 33 (2014): 195-197.

[10]Peng Wang, Li, Test aerosol fire extinguishing agent to the organic acid potassium salt combustible agent, J. Fire Science and Technology, 30 (2011): 404-408. 